\title{
Pemodelan Geobencana Tanah Runtuh Rayap Menggunakan Model Analog Mekanik
}

(Geohazard Modelling of Creeping Landslide by Mechanical-Analogue Model)

\author{
NOR SHAHIDAH MOHD NAZER*
}

\begin{abstract}
ABSTRAK
Tanah runtuh jenis rayapan merupakan salah satu fenomena geobencana yang sering terjadi dalam skala yang besar dan amat berkait rapat dengan perubahan tekanan air liang. Ia bercirikan canggaan jangka masa panjang maka dengan itu pengetahuan mendalam terhadap tindak balas rayapan di dalam keadaan tepu dan tidak tepu air adalah penting untuk meramal pergerakan masa hadapan. Kertas ini bertujuan mengkaji tindak balas rayapan di dalam sampel lempung bebola menggunakan kotak ricih terus yang terubah suai. Simulasi rayapan dibuat menggunakan model analog mekanik hasil gabungan spring dan peredam. Parameter $\gamma_{0}$ (pergerakan rayapan awal) yang diperoleh daripada ujian kotak ricih terubah suai digunakan sebagai input parameter bersama-sama dengan parameter lain yang diperoleh berdasarkan kaedah kuasa dua terkecil. Simulasi oleh model analog mekanik terhadap tindak balas rayapan yang direkod di makmal berjaya merakam tindak balas rayapan awal dan akhir. Keputusan kajian mendapati bahawa tindak balas rayapan adalah lebih signifikan di dalam keadaan tepu air berbanding keadaan tidak tepu air.
\end{abstract}

Kata kunci: Geobencana; lempung; model analog mekanik; rayapan; tanah runtuh

\section{ABSTRACT}

Creeping landslide is one of the big-scale geohazard phenomenon which closely related with changes in pore water pressure. It is characterized as long-term deformation; therefore, an in-depth knowledge of creep response under saturated and unsaturated condition is vital to project future movements. This paper examines creep response in Ball clay samples by means of modified direct shear box. Creep simulation was performed by mechanical-analogue model built upon springs and dashpots combinations. The parameter $\gamma_{o}$ (initial creep movements) gained from modified direct shear box tests is used together with other parameters determined by the least-square method. Mechanical-analogue model simulations based on creep response recorded in the laboratory have successfully captured the initial and final creep response. The research finding showed that creep response was more significant under water-saturated conditions rather than unsaturated conditions.

Keywords: Creeping; geo-hazard; landslide; mechanical-analogue model

\section{PENGENALAN}

Tanah runtuh merupakan geobencana yang amat signifikan di Malaysia dan direkodkan berlaku saban tahun. Seringkali tanah runtuh dikaitkan dengan proses gelinciran tanah yang berlaku akibat pengaruh air hujan yang melemahkan struktur tanah sekaligus mengakibatkan ketidakstabilan cerun. Hujan lebat disusuli oleh pergerakan cerun boleh mendatangkan kemudaratan daripada segi kerosakan rumah, bangunan, jalan raya serta secara tidak langsung membahayakan nyawa manusia. Gelongsoran tanah jenis translasi adalah pergerakan tidak berkala dan lazimnya berlaku untuk sela masa yang lama. Memandangkan ia dicirikan sebagai canggaan jangka-panjang, maka pengurusan tanah yang cekap perlu dititikberatkan bagi kawasan yang terdedah dengan ancaman geobencana tanah runtuh.

Sistem amaran awal biasanya direka untuk meramal geobencana tanah runtuh dan mengenal pasti zon risiko bencana. Lazimnya, teknik pengesanan jarak jauh (RS) digunakan untuk tujuan pengezonan bahaya tanah runtuh (Shu \& Yi 2015). Rekaan sistem amaran awal yang efektif dan praktik adalah penting bagi mengelakkan kepincangan dan pembaziran masa di saat kecemasan (Intrieri et al. 2013). Namun demikian, sistem amaran awal perlu mengambil kira data pemantauan di lapangan dan disokong oleh model mekanik yang direka sempurna bagi membolehkan jangkaan tepat terhadap pergerakan masa hadapan. Ini kerana, pemahaman terhadap mekanisma yang menyumbang ke arah kegagalan dan kajian terhadap hubung kaitnya dengan kinematik tanah runtuh adalah aspek penting bagi pencirian sesuatu model mekanik tanah runtuh (Nazer \& Tarantino 2016).

Apabila mempertimbangkan mekanisma kegagalan tanah runtuh, hubungan antara tekanan air liang dan hujan merupakan subjek yang menarik disebabkan sumbangannya terhadap pergerakan tanah runtuh yang tidak dapat dinafikan lagi (Bernardie et al. 2014; Ibrahim et al. 2015; Picarelli et al. 2004; Schulz et al. 2009). Menurut 
Ibrahim et al. (2014), resapan air hujan ke dalam tanah akan mengakibatkan perubahan tekanan matrik sedutan di bahagian sub-permukaan (zon tidak tepu). Pengaruh perubahan bermusim ke atas matrik sedutan mendatangkan penurunan signifikan terhadap kekuatan ricih tanah. Ini sekaligus mengakibatkan peningkatan tekanan liang dan akhirnya mencetuskan pergerakan cerun.

Pergerakan cerun sepanjang satah gelincir dikawal oleh sifat likat tanah lazimnya di dalam bentuk rayapan. Rayapan menyebabkan pergerakan cerun yang amat perlahan dalam suatu masa pada tekanan pemalar berkesan. Kajian mendapati cerun rayapan boleh bergerak pada kadar beberapa mm setahun dan pergerakan ini boleh berterusan untuk satu tempoh yang lama tanpa mencapai sebarang kegagalan (Picarelli et al. 2004). Tanah runtuh di Kundasang, Sabah merupakan salah satu tanah runtuh berskala besar yang bergerak secara rayapan (Liew \& Gue, 2001).

Sebahagian besar model rayapan di dalam kajian terdahulu yang berkait rapat dengan sistem amaran awal oleh tanah runtuh janaan hujan adalah bersifat empirik berbanding fizik (Furuya et al. 1999). Model empirik diketahui adalah terhad kepada keadaan sempadan tertentu dan tidak mempunyai penjelasan konsep yang jelas terhadap kinematik tanah runtuh. Oleh itu, model empirik adalah terbatas penggunaannya dan kekurangan daripada sudut teori asas pergerakan tanah runtuh (Huang et al. 2014).

Di dalam kajian ini, sasaran utama adalah simulasi tindak balas rayapan di dalam ricihan tanah berlempung tepu air dan tidak tepu air menggunakan model analog mekanik yang dibina hasil gabungan spring dan peredam. Melalui kaedah ini, rayapan di dalam tanah lempung dapat diukur pada dua keadaan tekanan air liang berbeza iaitu di dalam keadaan tepu air dengan tekanan liang adalah positif dan keadaan tidak tepu air dengan tekanan liang adalah negatif. Uji kaji dilakukan sepenuhnya di dalam makmal menggunakan kotak ricih terus yang telah terubah suai dan parameter yang diperoleh daripada ujian makmal (pergerakan awal rayapan, $g_{0}$ ) digunakan di dalam pemodelan simulasi rayapan.

\section{PENYEDIAAN SAMPEL}

Sampel yang digunakan sepanjang kajian adalah sampel lempung bebola di dalam bentuk serbuk. Sampel lempung bebola merupakan tanah lempung berlodak yang mengandungi $74 \%$ kandungan lempung dan 26\% kandungan lodak. Berdasarkan Sistem Pengelasan Tanah Bersatu (USCS), sampel ini dikategorikan sebagai lempung tinggi keplastikan (Lopes 2016).

Dua jenis sampel lempung disediakan iaitu sampel tepu air (T) dan sampel tidak tepu air (TT). Bagi sampel tepu air (T), ia disediakan dengan cara membentuk pes lempung hasil percampuran serbuk lempung bebola dan air suling sehingga mencapai kandungan air 100\% (lebih kurang 1.5wi). Pes lempung yang terhasil diletakkan di dalam kotak ricih bersaiz $60 \times 60 \mathrm{~mm}$ dan dibiarkan terkonsolidat dengan berat penutup bebanan (lebih kurang $2.7 \mathrm{kPa}$ ) selama satu hari. Bagi memastikan sampel kekal tepu air sepanjang tempoh uji kaji, kotak ricih dibiarkan terendam sepenuhnya oleh air. Kemudian, sampel dikonsolidat secara berperingkat sehingga mencapai tekanan normal $100 \mathrm{kPa}$.

Bagi sampel tidak tepu air (TT), kaedah yang sama diguna pakai namun perbezaannya adalah ketiadaan air di dalam kotak ricih sepanjang tempoh konsolidat. Setelah sampel selesai dikonsolidat secara berperingkat sehingga mencapai tekanan normal $100 \mathrm{kPa}$, sampel dikeluarkan daripada kotak ricih dan dikeringkan dengan udara sehingga mencapai jumlah kandungan air yang dikehendaki. Bagi kajian ini, kandungan air 29\% dipilih bagi mewakili sampel tidak tepu air dan nilai ini menghampiri had plastik sampel lempung bebola iaitu $24 \%$. Semua ujian dijalankan di dalam bilik kawalan suhu.

\section{KAEDAH KAJIAN}

Kerayapan di dalam ricih diuji berdasarkan ujian kawalan tekanan yang dijalankan menggunakan kotak ricih terubah suai (Rajah 1). Pengubahsuaian meliputi penambahan sistem takal yang diletakkan secara bersiri terhadap sel beban. Daya tegangan yang dikenakan oleh sistem takal terhadap bingkai atas kotak ricih terubah suai akan bertukar kepada daya ricih yang dikenakan pula ke atas spesimen yang terletak di dalam kotak ricih. Uji kaji dijalankan dengan cara menjana daya ricih secara berperingkat untuk mencapai tekanan ricih yang dikehendaki. Tekanan ricih yang dipilih bagi ujian ini adalah kurang 50\% daripada kekuatan ricih puncak spesimen lempung bebola. Sejurus mencapai tahap tekanan ricih yang dikehendaki, spesimen akan dikekalkan di dalam keadaan tekanan ricih seragam selama sehari bagi membenarkan pergerakan secara rayapan berlaku dan direkodkan.

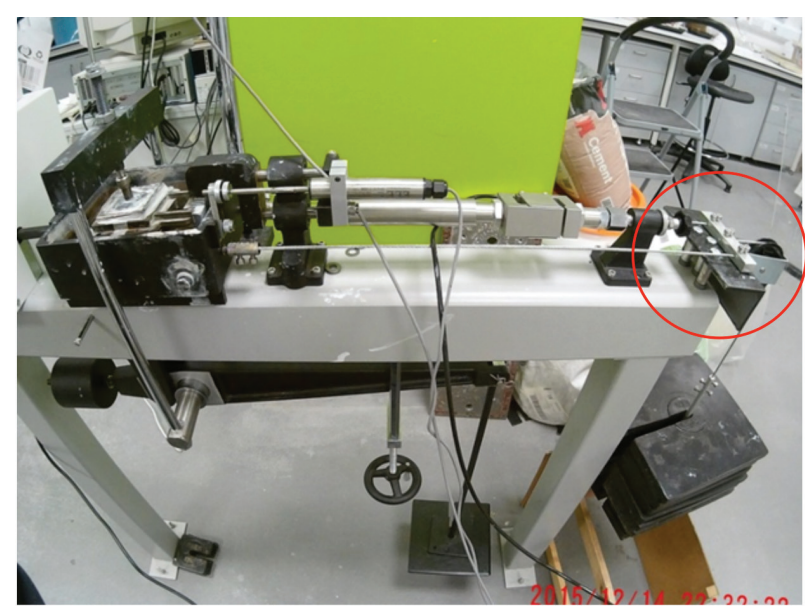

RAJAH 1. Kotak ricih terubah suai beserta sistem takal (bulatan merah) akan menghasilkan daya tegangan yang bertukar kepada daya ricih bagi mengerakkan sampel lempung bebola secara rayapan 


\section{KEPUTUSAN DAN PERBINCANGAN}

Rajah 2 menunjukkan keputusan tindak balas rayapan dan simulasi tanah lempungr bebola tepu air bagi spesimen bertanda T-K50. Spesimen T-K50 yang telah terkonsolidat pada tekanan normal $100 \mathrm{kPa}$ dikenakan tekanan ricih sebanyak $27.2 \mathrm{kPa}$ secara berperingkat, iaitu tekanan ricih yang lebih rendah berbanding kekuatan ricih puncak. Rajah 3 menunjukkan model analog mekanik yang dibangunkan untuk simulasi tindak balas rayapan spesimen T-K50. Simulasi tersebut terhasil berpandukan kepada persamaan konstitutif berikut:

$$
\gamma=\underbrace{\left\{\left[1-\exp \left(1 \frac{t}{\tau_{2}}\right)\right] \frac{G_{1}+G_{3}}{G_{2}}+1\right\} \gamma(0)}_{J(t)} \quad \tau_{2}=\frac{\eta_{2}}{G_{2}}
$$

dengan $\mathrm{J}(\mathrm{t})$ ialah pekali rayapan; $\gamma$ ialah alihan mengufuk (rayapan); $t$ ialah masa; $\mathrm{G}_{1}, \mathrm{G}_{2}$ dan $\mathrm{G}_{3}$ ialah kekakuan spring; $h_{2}$ ialah kelikatan peredam; dan $g_{0}$ ialah pergerakan awal rayapan.

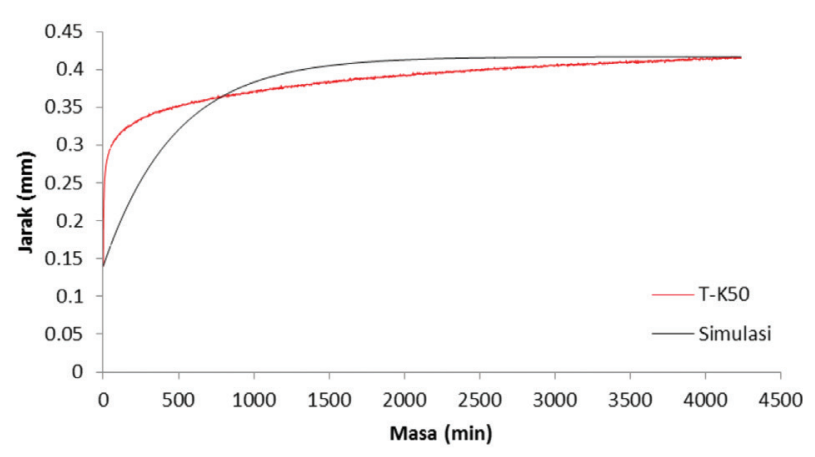

RAJAH 2. Tindak balas rayapan dan simulasi oleh model $\mathrm{AM} 3+1$ bagi spesimen tepu air, T-K50

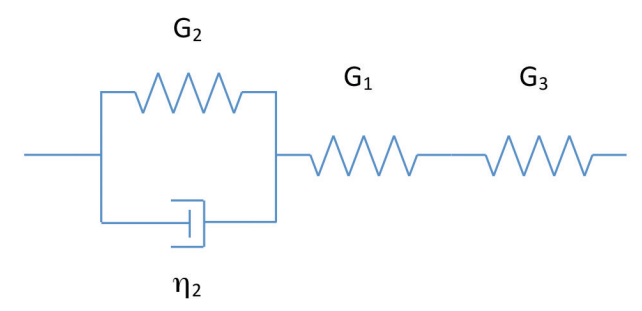

RAJAH 3. Model AM3+1 hasil gabungan 3 spring dan 1 peredam

Simulasi tindak balas rayapan oleh model AM3+1 di dalam spesimen lempung bebola tepu air adalah memuaskan dengan simulasi dilihat berjaya merakam tindak balas rayapan awal dan rayapan akhir yang diuji dalam tempoh sehari. Rayapan yang direkodkan ini merupakan rayapan primer berdasarkan kadar canggaan yang menurun dengan pertambahan masa. Memandangkan hanya satu peredam digunakan di dalam model AM3+1, sebahagian daripada tindak balas likat tidak tersimulasi dengan sempurna. Masalah ini boleh diselesaikan dengan cara menambah bilangan peredam pada model namun ia di luar konteks kajian ini. Penambahbaikan model boleh dilakukan pada kajian akan datang.

Rajah 4 menunjukkan keputusan tindak balas rayapan di dalam tanah lempung tidak tepu air bagi spesimen bertanda TT29-K50. Spesimen TT29-K50 mempunyai kandungan air 29\% dan terkonsolidat pada tekanan normal yang sama sebagaimana spesimen T-K50, iaitu $100 \mathrm{kPa}$. Memandangkan tekanan ricih puncak bagi spesimen tidak tepu air adalah lebih tinggi berbanding tekanan ricih puncak, spesimen tepu air akibat faktor kehadiran sedutan matrik menambah kekuatan ricihan tanah (Liansheng et al. 2016), maka nilai tekanan ricih $75.8 \mathrm{kPa}$ dipilih untuk kajian tindak balas rayapan pada spesimen tidak tepu air. Nilai ini masih berada pada keadaan kurang 50\% kekuatan ricih puncak dan adalah setara bagi tujuan perbandingan tindak balas ricih pada spesimen tepu air. Simulasi tindak balas rayapan oleh model AM3+1 ke atas spesimen juga dilihat memuaskan dengan nilai rayapan awal yang digunakan sebagai input parameter di dalam pemodelan berjaya merakam pergerakan rayapan akhir spesimen tidak tepu air dengan jayanya. Rayapan primer yang direkod pada spesimen tidak tepu air mempunyai kadar pergerakan rayapan yang lebih rendah berbanding spesimen tepu air. Ini sekali lagi dikaitkan dengan kehadiran matrik sedutan di dalam spesimen tidak tepu air yang bertindak meningkatkan daya kejelekitan antara butiran tanah sekaligus merendahkan kadar pergerakan secara rayapan bagi tanah yang kurang kandungan air. Tindak balas likat di dalam rayapan masih tidak tersimulasi sempurna dan hal ini telah diperjelaskan sebelum ini.

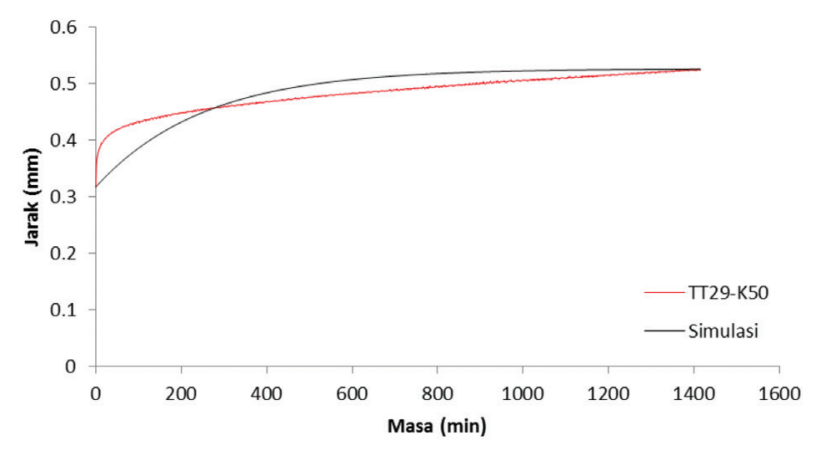

RAJAH 4. Tindak balas rayapan dan simulasi oleh model AM3+1 bagi spesimen tidak tepu air, TT29-K50

Penentuan keberjayaan simulasi dibuat dengan membandingkan nisbah rayapan akhir $\gamma_{\infty}$ kepada $g_{0}$ antara model dan ujian makmal berdasarkan persamaan berikut:

$$
\frac{\gamma_{\infty}}{\gamma_{0}}=\frac{G_{1}+G_{2}+G_{3}}{G_{2}}
$$

Jadual 1 menunjukkan parameter bagi kedua-dua keadaan tepu dan tidak tepu air. Parameter $G_{1}, G_{2}, G_{3}$ 
JADUAL 1. Parameter bagi spesimen tepu air T-K50 dan tidak tepu air, TT29-K50

\begin{tabular}{|c|c|c|c|c|c|c|}
\hline & $\tau_{0}$ & $\gamma_{0}$ & $\mathrm{G}_{1}$ & $\mathrm{G}_{2}$ & $\mathrm{G}_{3}$ & $\eta_{2}$ \\
\hline & $\mathrm{kPa}$ & $\mathrm{mm}$ & $\mathrm{kPa}$ & $\mathrm{kPa}$ & $\mathrm{kPa}$ & $\mathrm{kPa} \cdot \min$ \\
\hline TT29-K50 & 75.8 & 0.3 & 367.0 & 289.8 & 147.1 & $1.4 \mathrm{E}+05$ \\
\hline T-K50 & 27.2 & 0.1 & 27.3 & 56.7 & 40.0 & $7.5 \mathrm{E}+04$ \\
\hline
\end{tabular}

JADUAL 2. Nisbah $\gamma_{\infty} / g_{0}$ dan ralat antara model dan data makmal

\begin{tabular}{lccc}
\hline & $\gamma_{\infty} / \gamma_{0}$ Model & $\gamma_{\infty} / \gamma_{0}$ Data makmal & Ralat \\
\hline TT29-K50 & 1.66 & 1.65 & 0.00 \\
T-K50 & 2.98 & & 0.00 \\
\hline
\end{tabular}

dan $\mathrm{h}_{2}$ ditentukan secara kaedah kuasa dua terkecil menggunakan perisian SOLVER Microsoft Excel. Jadual 2 pula menunjukkan nisbah $\gamma_{\infty} / g_{0}$ antara model dan data makmal. Ralat bagi kedua-duanya adalah kosong sekaligus menggambarkan kemampuan model AM3+1 untuk mensimulasi tindak balas rayapan di dalam tanah lempung dengan cemerlang. Berdasarkan perbandingan nilai nisbah rayapan antara spesimen tepu air dan tidak tepu air, kadar rayapan adalah tinggi dengan pertambahan nilai kandungan air. Berdasarkan perkaitan di lapangan, pergerakan rayapan primer yang ditonjolkan oleh setiap cerun tidak tepu air (kedudukan di atas paras air bawah tanah) akan meningkat sewaktu hari hujan akibat pengaruh resapan air hujan yang meningkatkan tekanan air liang dan mengurangkan daya ricih cerun. Kadar pergerakan rayapan primer akan berubah ke tahap sekunder dan tertiar (kegagalan cerun) berdasarkan kandungan air yang meresap ke dalam cerun dengan perubahan mendadak tekanan air liang daripada sangat negatif kepada kurang negatif atau menghampiri positif menandai struktur tanah yang semakin lemah dan menghampiri kegagalan.

\section{KESIMPULAN}

Kertas ini membentangkan data makmal dan pemodelan ke atas tindak balas rayapan tanah lempung bebola dalam dua keadaan berbeza, iaitu tepu air dan tidak tepu air. Tindak balas rayapan dikaji selama satu hari pada tekanan ricih yang lebih rendah berbanding kekuatan ricih puncak menggunakan kotak ricih terus yang terubah suai. Parameter $\mathrm{g}_{0}$ pergerakan awal rayapan) direkodkan daripada uji kaji makmal dan digunakan sebagai input parameter di dalam model analog mekanik untuk simulasi rayapan tanah lempung bebola. Model AM3+1 yang dibangunkan hasil gabungan spring dan peredam berjaya mensimulasi semula pergerakan rayapan primer, dengan kadar canggaan adalah perlahan dengan pertambahan masa. Berdasarkan hasil yang diperoleh, model AM3+1 dijangka mampu mensimulasi pergerakan rayapan bagi tempoh yang lebih lama, meliputi rayapan sekunder hingga ke rayapan tertiar dan kegagalan ricih akan mula berlaku. Model ini berpotensi untuk dibangunkan sebagai sistem amaran awal bagi pencegahan kejadian tanah runtuh jenis rayapan di bawah pengaruh hujan.

\section{PENGHARGAAN}

Ucapan terima kasih tidak terhingga buat Professor Alessandro Tarantino daripada University of Strathclyde untuk segala tunjuk ajar, keputusan kajian dan data yang diperoleh.

\section{RUJUKAN}

Bernardie, S., Desramaut, N., Malet, J.P., Gourlay, M. \& Grandjean, G. 2015. Prediction of changes in landslide rates induced by rainfall. Landslides 12(3): 481-494.

Furuya, G., Sassa, K., Hiura, H. \& Fukuoka, H. 1999. Mechanism of creep movement caused by landslide activity and underground erosion in crystalline schist, Shikoku Island, southwestern Japan. Engineering Geology 53(3): 311-325.

Huang, W., Liu, D.Y., Zhao, B.Y., Feng, Y.B. \& Xia, Y.C. 2014. Study on the rheological properties and constitutive model of Shenzhen mucky soft soil. Journal of Engineering Science and Technology Review 7(3): 55-61.

Ibrahim, A., Mukhlisin, M. \& Jaafar, O. 2014. Rainfall infiltration through unsaturated layered soil column. Sains Malaysiana 43(10): 1477-1484

Intrieri, E., Gigli, G., Casagli, N. \& Nadim, F. 2013. Brief communication - Landslide early warning system: Toolbox and general concepts. Natural Hazards and Earth System Sciences 13(1): 85-90.

Liansheng, T., Haitao, S., Liqun, J. \& Yinlei, S. 2016. New progress in the study of intergranular suction and shear strength of unsaturated soil. Sains Malaysiana 45(1): 141156.

Liew, S.S. \& Gue, S.S. 2001. Massive creep movements of post-glacial deposits in Kundasang areas. GSM-IEM Forum: Engineering Geology and Geotechnics of Slopes. hlm. 13.

Lopes, B.D.C.F.L. 2016. Microstructural-based approach to the interpretation of clays and transitional soils behaviour. Thesis $\mathrm{Ph}$. D, University of Brasil (tidak diterbitkan). 
Nazer, N.S.M. \& Tarantino, A. 2016. Creep response in shear of clayey geo-materials under saturated and unsaturated conditions. E3S Web of Conferences. Vol. 9. EDP Sciences.

Picarelli,L., Urciuoli, G. \& Russo, C. 2004. Effect of groundwater regime on the behaviour of clayey slopes. Canadian Geotechnical Journal 41(3): 467-484.

Schulz, W.H., McKenna, J.P., Kibler, J.D. \& Biavati, G. 2009. Relations between hydrology and velocity of a continuously moving landslide-evidence of pore-pressure feedback regulating landslide motion? Landslides 6(3): 181-190.

Shu, R.Y. \& Yi, L.Y. 2015. Geologic hazard risk assessment of slopeland villages in Southern Taiwan using remote sensing techniques. Sains Malaysiana 44(12): 1677-1683.
Geology Program

School of Environmental and Natural Resource Sciences

Faculty of Science and Technology

Universiti Kebangsaan Malaysia 43600 UKM Bangi, Selangor Darul Ehsan Malaysia

*Pengarang untuk surat-menyurat; email: shahidahnazer@ukm. edu.my

Diserahkan: 12 April 2017

Diterima: 1 Jun 2017 